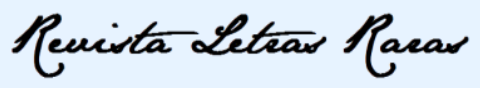

ISSN: 2317-2347 - v. 7, n. 1 (2018)

\title{
Do Teatro de Revista às incorporações da Broadway em palcos tupiniquins: singularidades, inspirações e desafios na história do Teatro Musical brasileiro / Of the magazine theater to the incorporations of Broadway in stages tupiniquins: singularities, inspirations and challenges in the history of the brazilian Music Theater
}

\author{
Raimundo Expedito dos Santos Sousa* \\ Éderson Luís Silveira** \\ Magda Veloso Fernandes de Tolentino ***
}

\begin{abstract}
RESUMO
O presente trabalho tem como objetivo proceder a um percurso panorâmico da história do Teatro Musical no Brasil, historicizando suas raízes e suas influências internas e externas considerando, como referencial teórico, os estudos de autores como Maluf e Aquino (2006), Prado (1999) e Riche e Gasparini (2010), entre outros. Assim, constrói-se uma linha do tempo que contextualiza a Ópera e o Cabaré, a emergência do Teatro de Revista brasileiro e sua evolução, bem como o Teatro Musical no contexto do Regime Militar e, finalmente, as atuais mega produções musicais inspiradas no modelo da Broadway. Tais expressões artísticas são exemplos de como, por meio de um trabalho de tradução cultural, padrões estéticos advindos de outros países são acomodados à cultura brasileira e assumem uma configuração específica, deixando de ser meras cópias ou importações. Tal proposta de investigação parte do pressuposto de que o Teatro de Revista no Brasil é mais que uma manifestação artística uma forma de manifestação e reprodução da linguagem em solo nacional que se constitui a partir de especificidades e filiações a partir de uma heterogeneidade tão rica e diversificada como a que constitui o povo brasileiro.

PALAVRAS-CHAVE: Teatro Musical; Brasil; história.
\end{abstract}

\section{ABSTRACT}

The present paper aims to carry out a panoramic route in the history of Musical Theater in Brazil, historicizando its roots and its internal and external influences, such as theoretical reference, studies of authors such as Maluf and Aquino (2006), Prado (1999) and Riche and Gasparini (2010), among others. Thus, it builds a timeline that contextualizes the Opera and Cabaret, the emergence of Brazilian Theater Magazine and its evolution, as well as musical theater in the context of the military regime, and finally the current mega musical productions based on the model of Broadway. Such artistic expressions are examples of how, through a work of cultural translation, aesthetic standards from other countries are accommodated to the Brazilian culture and assume a specific configuration, leaving of being mere copies or imports. Such research proposal assumes that the Revue in Brazil is more than an art a form of manifestation and reproduction of language on domestic soil that constitutes from specifics and affiliations from a heterogeneity as rich and diverse as the Brazilian people.

KEYWORDS: Musical theatre; Brazil, history.

\section{Introdução}

\footnotetext{
* Doutorando em Estudos Literários pela Universidade Federal de Minas Gerais - UFMG; Bolsista FAPEMIG. raimundo_sousa@terra.com.br

** Mestre e Doutorando em Linguística pela Universidade Federal de Santa Catarina-UFSC; pósgraduando em Ontologia e Epistemologia, Membro e pesquisador do Grupo Formação de Professores de Línguas e Literatura (FORPROLL/CNPq) e do Grupo Michel Foucault e os Estudos Discursivos (UFAM/ CNPq). Bolsista CAPES.ediliteratus@gmail.com

***Professora Doutora de Estudos Literários no Programa de Pós-Graduaçao em Letras da Universidade Federal de São João Del-Rei - UFSJ . magdatolentino@ hotmail.com
} 


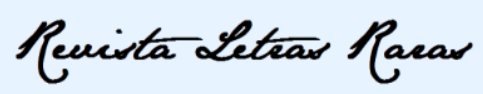

ISSN: 2317-2347 - v. 7, n. 1 (2018)

O Teatro Musical norte-americano é um gênero internacionalmente conhecido, de grande popularidade, que consolidou uma forma de fazer teatro: o "modelo Broadway". Esse padrão Broadway, com raízes europeias, sempre exerceu grande influência na cena teatral brasileira. No entanto, em um país musical como o Brasil, onde a inspiração com a arte pode emergir em cada esquina, em cada região com características distintas, esse casamento entre os teatros norte-americano, europeu e brasileiro, acabou por fazer nascer um novo estilo que, ao longo do tempo, foi se modificando e se reinventando de acordo com a sociedade de cada época.

Da Opereta carioca ao Teatro de Revista, do musical político e engajado de Chico Buarque, por exemplo, à importação de espetáculos da Broadway e os espetáculos musicais biográficos, a sociedade brasileira convive há mais de um século com esse estilo musical de fazer teatro ${ }^{1}$. Cada época a sua maneira, com suas problemáticas, com seu estilo. No entanto, apesar de a cena musical existir no Brasil há muitos anos, ela ainda é relativamente nova e está, hoje, em um momento de expansão e assimilação por parte do público, da crítica e também dos profissionais envolvidos.

Nesse sentido, este trabalho busca contribuir para a historiografia do Teatro Musical no Brasil ao proceder a uma pesquisa bibliográfica, fundamentada no levantamento de obras de referência, resultando em contribuições relacionadas a uma apresentação do estado da arte acerca da evolução histórica e estética no Teatro Musical no Brasil. Severino (2007), por exemplo, parte da subdivisão da história do Teatro de Revista em três fases: a primeira fase, na qual a construção de um enredo coeso e bem articulado era menos visada do que a articulação entre a estética corporal dos atores e a capacidade de empreender críticas aos modos de vida citadinos; a segunda fase, na qual a cultura popular estadunidense se faz presente por meio do blues e do jazz chegada da companhia francesa Ba-ta-clan ao país que pôs em cena a nudez da corporeidade feminina; a terceira, na qual se destacaram os fartos investimentos em grandes espetáculos. A partir de tais considerações este trabalho aborda os diferentes gêneros de

\footnotetext{
${ }^{1}$ Macau (2016, s. p.) menciona que os brasileiros "são os maiores frequentadores estrangeiros dos shows da Broadway, atrás apenas dos ingleses, de acordo com pesquisas da organização oficial de marketing e turismo da cidade de Nova York, a NYC \& Company". Frequentemente, o Brasil é apontado como sendo o terceiro maior consumidor de Teatro Musical do Mundo, atrás apenas dos Estados Unidos e da Inglaterra.
} 


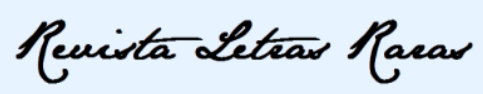

ISSN: 2317-2347 - v. 7, n. 1 (2018)

teatro musical no decorrer nos anos, suas adversidades, seus revezes, desenlaces e triunfos.

Vale destacar que, desde o surgimento, o Teatro de Revista no Brasil, no século XIX, ganhou destaque principalmente no Rio de Janeiro e em São Paulo como uma das principais expressões do teatro nacional. Se atualmente os estudos historiográficos do Teatro de Revista permitem advertir sobre as particularidades é preciso considerar que, neste caso, trata-se da utilização de textos de teatro em que a ação dependia da música para o seu desenvolvimento progressivo. Para fomentar tais considerações, o referencial teórico será utilizado a partir dos estudos de autores como Maluf e Aquino (2006), Prado (1999), Riche e Gasparini (2010), entre outros justamente porque se trata de autores que apontam para especificidades do Teatro Musical no Brasil, conforme será mostrado adiante. Para isso, a seção 2 vai apresentar algumas considerações acerca do Teatro de Revista no Brasil, a seção 3 sobre o Teatro Musical brasileiro focando no surgimento, na marginalização e na posterior ascensão do gênero. Na seção 4 será apresentado um exemplo de adaptação de teatro musical estrangeiro no Brasil e na última seção serão retomados os pontos principais da discussão empreendida.

\section{Teatro de Revista no Brasil}

O desenvolvimento do teatro de revista no Brasil se deu a partir de continuidades e rupturas, de modo que é possível traçar sua evolução histórica e estética focalizando algumas fases que, grosso modo, acabaram definindo sua configuração em diferentes contextos históricos e culturais.

A primeira semente veio em meados do século XIX: As Operetas, um tipo de Ópera mais curta e de temas mais leves e divertidos, uma espécie de teatro musicado no qual se alternava canto e fala. $O$ gênero, importado da Europa (principalmente da Itália e da França), tinha suas obras originais adaptadas por autores brasileiros que traduziam e adaptavam o texto (libreto), enquanto mantinham a estrutura musical (partitura), até que, com a experiência, apareceram nossos próprios compositores, bem como as primeiras operetas nacionais. Acompanhando esse desenvolvimento, ainda no século XIX, o público brasileiro recebeu uma segunda influência: O Teatro de Revista. De origem Francesa, derivado do Vaudeville (ou Teatro de Variedades), e trazido por imigrantes portugueses. O Teatro de Revista despontou 


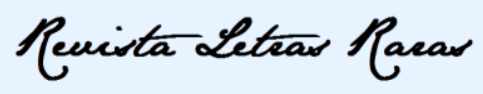

ISSN: $2317-2347$ - v. 7, n. 1 (2018)

com esquetes e números musicais, críticas sociais e políticas, o uso do cômico, da sensualidade feminina, e de um apelo bastante popular (MENSCH CULTURA, 2014, s. p.).

Assim, no Brasil, como na Opereta Carioca, o Teatro de Revista foi imediatamente povoado de malandros, mulatas, caipiras, portugueses, etc.; elementos estes, que foram sendo somados a acontecimentos sociais, políticos e à música popular brasileira. Conforme a crítica de arte Neyde Veneziani (2012), o Teatro de Revista surgiu no Brasil em meados do século XIX. Com o decorrer do tempo, foi considerado o mais importante e expressivo gênero no sentido de produção teatral no país, destacando-se principalmente no Rio de Janeiro e em São Paulo. Em outro texto, Veneziani (1991) explana que, ao contrário das outras modalidades, a revista é um gênero teatral fragmentado, que se adapta às características do país no qual é produzida. Dessa forma, o Teatro de Revista, segundo Veneziani (1991; 1996), não se aclimatou facilmente à cultura brasileira, pois foram várias as tentativas até que finalmente conseguisse o efeito esperado. Severino (2007), por exemplo, historiciza o desenvolvimento do teatro de revista brasileiro a partir de três fases. Ao discorrer sobre a primeira delas, o autor a define nos seguintes termos:

Na primeira fase, o Teatro de Revista não exigia uma linha narrativa. A principal característica neste momento era ter um casal de cantores e bailarinos que deviam seguir a regra de ela ser obrigatoriamente elegante e bonita, e ele alegre e malandro, colocando um toque de sátira em cada frase e em cada nova sequência do espetáculo, ao mesmo tempo em que se revelava a hipocrisia da sociedade (SEVERINO, 2007, p. 37).

Nesse estágio inicial, podemos observar que a construção de um enredo coeso e bem articulado era menos visada do que a articulação entre a estética corporal dos atores e a capacidade de empreender críticas aos modos de vida citadinos.

Os elementos que caracterizam o teatro de revista são demonstrativos disso. Composto por diversas influências, como a ópera-cômica, a opereta, o vaudeville, era o gênero mais popular de espetáculo característico do Rio de Janeiro no qual se destacavam como elementos composicionais o texto em verso, a presença da comédia musicada, o fandango, o samba e, em tempos modernos, a bossa nova (MENCARELLI, 1999). 


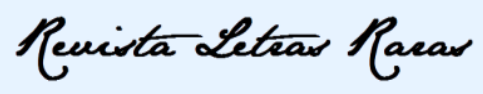

ISSN: 2317-2347 - v. 7, n. 1 (2018)

Conforme Prado (1999), os textos desse novo gênero precisavam de música para funcionar, ou seja, eram textos de teatro em que a ação dependia da música para o seu desenvolvimento progressivo. Mesmo que uma parte das canções tenha apenas o caráter ilustrativo, a alma e o sentido dos textos estão nas músicas. De fato, existiam casos em que as músicas eram realidades autônomas, independentes e que foram incorporadas a uma proposta de espetáculo posterior a elas. Eram músicas com existência anterior, que precediam o ato teatral, mas que conquistavam outra existência a partir de uma nova proposição cênica e original, com a função de ajudar a carregar a ação dramática.

Essa primeira fase, que se estendeu até por volta da década de 1910, foi sucedida por uma segunda fase, na qual se destaca a presença, cada vez mais incisiva, da cultura popular estadunidense na música e, por extensão, no Teatro de Revista (SEVERINO, 2007). Na década de 1920, torna-se pungente a presença de estilos musicais estadunidenses como o blues e o jazz na cultura brasileira, haja vista a iniciativa da companhia teatral capitaneada por Jardel Jércolis, que ousou substituir sua orquestra de cordas por uma banda de jazz. Além disso, a performance corporal do maestro, que aos poucos foi se consolidando como elemento partícipe do espetáculo, ratificava a influência musical dos Estados Unidos nessa segunda fase (MAGALDI; VARGAS, 2000).

Nessa segunda fase do desenvolvimento do Teatro de Revista no Brasil ocorre a chegada da companhia francesa Ba-ta-clan ao país, nos idos de 1920. Essa companhia, segundo Maluf e Aquino (2006), trouxe consigo novas tendências para essa expressão artística, na medida em que pôs em cena a nudez da corporeidade feminina, deixando-a mais à mostra do que já estava. Nesse sentido, o corpo da mulher adquiriu mais relevância, pois recaía sobre ele maior ênfase em performances como a dança, de maneira que o corpo feminino se firmava como um elemento não apenas coreográfico como, também cenográfico, enquanto paisagem corporal.

Com a multiplicação de companhias de Teatro de Revista e com a assunção de características próprias por cada uma delas, começa-se a desenvolver uma competitividade sutil e velada entre as companhias e, especificamente, entre as estrelas de cada uma delas. Ao disputarem o gosto do espectador, inserindo-se em um mercado musical incipiente, as companhias eram obrigadas a lançar mão de diversos recursos estilísticos e essa busca pelo aperfeiçoamento contínuo acabou contribuindo para o 


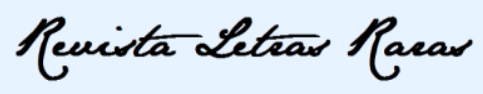

ISSN: 2317-2347 - v. 7, n. 1 (2018)

desenvolvimento do Teatro de Revista em termos de qualidade e criatividade (RIECHE; GASPARINI, 2010).

Finalmente, a terceira e última fase foi a do investimento em grandes espetáculos. Atingiu seu clímax nas produções de Walter Pinto (renovador do gênero), o Teatro de Revista Brasileiro. Sua companhia substitui o interesse dos primeiros atores pela credibilidade da empresa na produção de grandes espetáculos, em que um elenco formado por numerosos artistas se reveza em cada temporada (MALUF; AQUINO, 2006). Todavia, a despeito de sua trajetória bem-sucedida no transcurso de mais de um século de existência, o Teatro de Revista entra em declínio nas últimas décadas do século XX, em decorrência, sobretudo, da dificuldade em concorrer com novas formas de entretenimento vinculadas à expansão da indústria cultural, como a televisão. Além disso, entraves como a dificuldade em angariar recursos financeiros necessários à criação de grandes espetáculos e a atuação da censura durante o regime ditatorial dos anos 1960 a 1980 concorreram para o declínio do Teatro de Revista, o que perdurou nos anos posteriores até os dias atuais (VENEZIANO, 1991; 1996).

\section{Notas sobre o Teatro Musical brasileiro}

De acordo com Budasz (2008), para os brasileiros, o Teatro Musical parece constituir uma descoberta muito recente; mas, na realidade, tem sido praticado quase continuamente desde o século XIX. O fato é que a história do Teatro brasileiro tem negligenciado o Teatro Musical de tal modo que ainda há muito o que se descobrir sobre ele, o que o torna um campo fértil para a pesquisa, como observa Silva (2010):

A História do Teatro Brasileiro ainda não incorporou a pulsante trajetória do teatro musical produzido no país, gênero reduzido, nos principais autores, quando muito, a referências passageiras ou restritivas. Diante da riqueza da vertente artística e do fascínio que exerce junto a um grande público, é fundamental atuar a favor de uma reflexão crítica sobre a linha de trabalho. Trata-se de um campo pródigo em controvérsias e atraente por sua variedade impressionante de formas e projetos, além das múltiplas habilidades que solicita. Em princípio, pesquisá-lo significa olhar o palco do Rio de Janeiro, centro em que nasceu e se afirmou e de onde irradiou para diversas regiões do país; a observação não é bairrista e não deseja ser uma forma de exclusão das potências regionais. (SILVA, 2010, p. 1). 


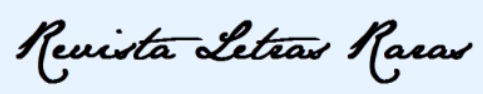

ISSN: $2317-2347$ - v. 7, n. 1 (2018)

Conforme esse estudioso, o Teatro Musical no Brasil se originou sob a influência da França e de Portugal e alcançou um sucesso considerável e rápido, a despeito de muitos escritores e intelectuais terem combatido o gênero com veemência uma vez que o consideravam indecoroso e alheio às tradições culturais nativas. Dudasz (2008) ainda acrescenta que, na metade do século XIX, a Empresa Joaquim Helidoro inaugurou o Ginásio Dramático, cuja plataforma de trabalho pretendia a consolidação do teatro realista, de extração francesa. Apesar da seriedade do Ginásio Dramático, foi em seu palco que se apresentou a primeira revista brasileira, qual seja, o espetáculo As Surpresas do Sr. José da Piedade, produzido por Justiniano de Figueiredo Novaes. Esse empreendedor inovou as peças teatrais, transformando-as em operetas e ações curtas, todas de caráter satírico de inspiração francesa. Por sua vez, o Teatro Ginásio do Rio de Janeiro, situado no Rio de Janeiro, foi inaugurado em 1859, tendo como fundador o empresário francês Monsieur Arnaud. Esse Teatro permaneceu em atividade até o final do decênio de 1880, tendo apresentado diversos musicais ao longo de seu tempo de funcionamento. Tratava-se de um teatro em formato de café-concerto ou cabaré e que tinha como norte estilístico o boulevard e a opereta de caráter triunfante (GUINSBURG; FARIA; LIMA, 2006).

De acordo com Dudasz (2008), Orfeu no inferno, escrita por Ofenbach, foi a primeira opereta francesa produzida no Brasil. Após estrear em Paris, na década de 1850, foi trazida para o Brasil e apresentada em 1865. O fato de essa opereta ser importada poucos anos após sua produção na França demonstra como a interlocução cultural entre Brasil e França era intensa e de como os artistas brasileiros estavam atentos às novidades advindas da Europa.

É preciso ressaltar, novamente, o modo como essas produções artísticas desafiavam os códigos morais instituídos em um período de forte influência da Igreja Católica no Brasil. O êxito obtido pelo Teatro Musical em um contexto de grande repressão sexual demonstra o caráter subversivo da arte, pois, a mesma plateia brasileira que, no âmbito da vida priva, mostrava-se moralista e intolerante se deliciava com audaciosas produções como essa. De fato, essas operetas eram, em sua maioria, importadas da França, cuja cultura boêmia e liberal a tornava um centro de refúgio da intelectualidade subversiva do final do século XIX e início do XX, bem como um 


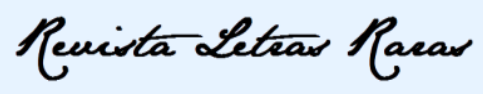

ISSN: 2317-2347 - v. 7, n. 1 (2018)

exemplo de má influência que deveria ser evitado - haja vista que romances e peças franceses eram perseguidos pelas lideranças moralistas, como observa Prado (1999).

Nesse sentido, conforme Veneziano (2012), é relevante mencionar que mesmo a elite letrada brasileira que, em tese, seria mais tolerante com relação às inovações artísticas advindas das vanguardas europeias, insurgia-se com rispidez contra o Teatro Musical. A crítica do escritor brasileiro Machado de Assis2, por exemplo, afeito à cultura francesa, demonstra que a contraposição dos intelectuais brasileiros a esse gênero não se devia propriamente à importação de uma expressão artística europeia, mas, sim, ao modo como se dava essa apropriação, que, ao ver dos escritores tradicionais, errava ao adaptar de maneira supostamente equivocada e de mal gosto um teatro consagrado na Europa.

A acomodação de produções artísticas francesas, como aquelas vinculadas ao Teatro Musical, assumia, assim, um papel de crítica dos costumes instituídos. Afinal, muitas das operetas trazidas para o Brasil tinham aspecto satírico, pois carnavalizavam a moral e os costumes vigentes, denunciando as contradições sociais e culturais de uma época marcada por opressões de classe, gênero e raça (GUINSBURG; FARIA; LIMA, 2006).

Embora este trabalho não tenha o objetivo de proceder a um estudo dos modos de recepção das produções artísticas pelo público, pode-se inferir, a partir de Dudasz (2008), que muito do aspecto crítico e intertextual das operetas e outras manifestações culturais importadas se perdia na apropriação para o português. Afinal, o pleno entendimento de uma opereta exigia, em seu aspecto intertextual, conhecimentos prévios sobre a arte dramática grega e, em seu âmbito crítico, um mínimo de conhecimento sobre a sociedade francesa.

Ao perceberem que o público em geral tinha dificuldade de apreender o teor satírico e intertextual das produções, produtores e artistas como o ator Francisco Correa Vasques procuraram fazer adaptações nos textos a fim de torná-los mais compreensíveis e em conformidade com a realidade brasileira. Assim, Vasques escreveu a primeira paródia brasileira, tomando por base a paródia francesa. Trata-se de Orfeu na Roça, uma releitura de Orfeu e Eurídice. Essa produção foi apresentada pela primeira vez em 1868,

2 De acordo com Veneziani (2010, p. 53), "Machado de Assis fez campanha declarada contra as meias tão justinhas que pareciam que as pernas estivessem nuas! Os jornais reclamaram, as senhoras católicas idem, os intelectuais exigiam um teatro sério nos moldes europeus-inteligentes." 


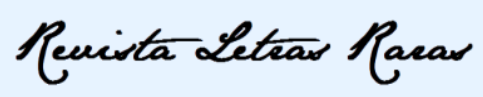

ISSN: 2317-2347 - v. 7, n. 1 (2018)

e obteve grande êxito de audiência, alcançando o recorde de mais de uma centena de apresentações consecutivas (MENCARELLI, 1999). O sucesso dessa produção deu maior fôlego ao teatro musical brasileiro, estimulando produções subsequentes. Porém, também teve um aspecto contraproducente, na medida em que instigou a fúria dos opositores a essa expressão artística que consideravam prejudicial à integridade moral do país.

No entanto, o Teatro Musical se expandiu de tal modo que sua contextualização se torna um desafio para o pesquisador da história da arte. Afinal, conforme observa Prado (1999), a definição do Teatro Musical no Brasil é extensa e absorve um vasto leque de manifestações. Abrange tanto o teatro musicado do século XIX, que reunia a revista (o mais popular gênero musical do século XX no Brasil), a mágica e a burleta, como a opereta (modalidade de espetáculo cuja trajetória é de extrema importância para toda a história do musical), a comédia musical, o drama musical e o que se chama hoje simplesmente de "musical".

Portanto, no caso brasileiro, o musical tomou forma mais nítida no início do século XIX, mas começou a se impor como acontecimento social e cultural no século XX. Entretanto, um duplo estigma o levou a um estatuto bastardo e inferiorizado: a ligação com as ruas e a aproximação com a comédia, que, na tradição erudita francesa, era considerada um gênero associado ao universo das pessoas comuns, conforme observa Silva (2010, p. 3):

A sua origem - se é que se pode falar nesses termos - seria a expressão popular, quer dizer, formas de manifestação sensível das pessoas comuns, das ruas, afastadas das academias e dos salões da grande arte. Ele seria um filho querido das feiras, mercados e praças, dos prostíbulos ou casas de diversão masculinas, das festas e manifestações do populacho, formas de passatempo urbano que, no caso brasileiro, começaram a se delinear com alguma clareza no século XVIII, para tomar forma mais nítida no início do século XIX e se impor como acontecimento social e - digamos - cultural na segunda metade do século XIX. Um duplo estigma, portanto, levou à sua redução a um estatuto inferior, bastardo - a ligação às ruas, às pessoas que se reduziam a uma existência física, puro corpo e nenhuma idéia (sic). E a consequente (sic) aproximação ao vasto edifício da comédia, que, na tradição erudita francesa, era o gênero associado ao universo das pessoas "comuns". (SILVA, 2010, p. 03).

Cabe acentuar que o teatro foi sempre um porto seguro para os mais importantes compositores do nosso país. Por ele passaram artistas renomados como Chiquinha 


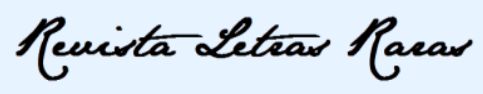

ISSN: $2317-2347$ - v. 7, n. 1 (2018)

Gonzaga, Tom Jobim, Ary Barroso e Carlos Gomes. Tais personalidades se valeram da música não somente como mero entretenimento, mas, também, como um instrumento de diálogo com o público, tematização de questões sociais candentes e formação de valores. Noutros termos, esses artistas se valeram da música como forma de interpretação da realidade e, mais ainda, como crítica dessa própria realidade que observavam com o olhar sensível peculiar aos artistas (FENERICK, 2005).

Referindo-se à importância do Teatro Musical para Chiquinha Gonzaga, Severino (2007) sublinha que a compositora procurou se valer do teatro, associado à canção, como instrumento para exercitar sua criatividade artística:

O teatro representou para ela a conquista de um público maior e o reconhecimento como compositora e um retorno financeiro seguro. Em 1880, ela escreveu um libreto e tentou musicá-lo, o que acabou como uma peça de costumes, Festa de São João (SEVERINO, 2007, p. 21, grifo do autor).

Também é digno de nota o papel desempenhado pelo Teatro Musical na formação de Ary Barroso. Advindo de família pobre e tendo crescido órfão, Ary Barroso contou com a sorte ao herdar a fortuna de um tio e, então, mudar-se nos anos 1920 do interior de Minas Gerais para o Rio de Janeiro, com a finalidade de cursar Direito. No entanto, o jovem gastou rapidamente todo o dinheiro que herdara e, ante a necessidade de se manter, começou a trabalhar como ajudante em cinemas e teatros. Assim, interessou-se pela arte e percebeu finalmente qual era sua inclinação. Em depoimento no qual relata seus anos iniciais no Rio de Janeiro, o artista deixa entrever como as expressões artísticas visuais, incluindo-se o teatro, tiveram papel relevante em sua formação:

[...] Meus primeiros dois anos de estudante correram mais ou menos tranqüilos. Até que terminou a 'grana'. Começou, aí, verdadeiramente, minha luta. Fiz-me pianista profissional. Estreei tocando em cinema, na sala de projeção do Cinema Íris. Depois, fiz parte da orquestra do Sebastião, tocando na sala de espera do antigo Teatro Carlos Gomes [...]. Daí, passei-me para a orquestra de J. Tomás, na sala de espera do Rialto. Comecei então a ser conhecido como pianista-jazz. Do Rialto, transferimo-nos para o Cinema Central, do grande empresário Pinkfild, que nos dava fita e palco (BARROSO, apud CABRAL, 1993, p. 29). 


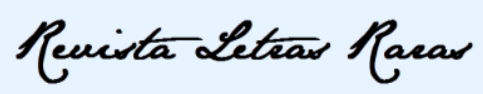

ISSN: 2317-2347 - v. 7, n. 1 (2018)

O papel desempenhado pelo teatro na carreira musical de Ary Barroso não deve ser subestimado, afinal, é significativo que sua produção mais famosa, Aquarela do Brasil, tenha sido apresentada pela primeira vez em um teatro (CABRAL, 1993). Independentemente da sua origem e de seu processo evolutivo na cultura brasileira, o desenvolvimento do Teatro Musical no Brasil constitui um divisor de águas na medida em que marca, ainda segundo Silva (2010), a emergência do palco como arte vinculada ao mercado, ou seja, está relacionada ao que mais tarde receberia o nome de cultura de massa ou, ainda, de indústria cultural. Trata-se de um fato relevante porque demonstra a inserção das pessoas comuns entre os consumidores de arte no Brasil. Ocorre, portanto, uma maior aproximação entre a arte e a população comum, até então desprovida de acesso aos bens culturais produzidos no país.

\subsection{A marginalização do Teatro Musical: anos sombrios}

O Teatro Musical no Brasil, e mais precisamente no Rio de Janeiro, conheceu detratores de todos os tipos: dos eruditos do século anterior, aos jovens dos anos 1940 desejosos de implantar o teatro moderno no país. Galante de Sousa (apud RIECHE; GASPARINI, 2010), por exemplo, reproduzia um ponto de vista comum a diversos outros intelectuais de seu tempo ao afirmar:

Ao lado da revista e da burleta, continuou sendo explorado, nos primeiros anos do século XX, o drama de capa e espada. Sem dúvida alguma, porém, o teatro musicado prejudicava a peça declamada. Positivamente a peça ligeira, oferecendo maior garantia comercial para autores e empresários, dificultava a expansão do teatro sério (SOUSA apud RIECHE; GASPARINI, 2010, p. 37).

Esse posicionamento apresenta uma concepção reducionista acerca da lógica mercantilizada que regia a produção artística no Brasil nas primeiras décadas do século XX. Esse reducionismo era perceptível na caracterização elitista das expressões artísticas, que relegava o Teatro Musical como manifestação cultural inferior, isto é, deficiente em termos de qualidade em comparação com o teatro convencional.

Essa avaliação negativa do Teatro Musical levou-o a uma gradativa marginalização do centro cultural brasileiro, dificultando a captação de recursos e a 


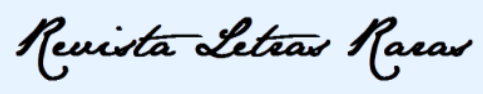

ISSN: 2317-2347 - v. 7, n. 1 (2018)

legitimação como arte genuína, conforme explicam Eduardo Rieche e Gustavo Gasparini:

\begin{abstract}
Houve, portanto, a cristalização de uma avaliação negativa contrária ao reconhecimento de méritos no teatro musical, muito embora o próprio país se afirmasse como uma terra musical. O resultado natural foi a condenação do espetáculo teatral musical ao gueto ou a espaços de segregação, a sua vinculação a formas de não-arte, pura manifestação de instintos, vistos, estes, como aquela parte do humano que se opõe ao ideal, ao espírito e à nobreza de caráter. A partir daí, é fácil compreender a luta do teatro moderno contra o teatro musical, o seu enfraquecimento decisivo ao longo da década de 1950, a sua aproximação, a partir desta época, das artes do carnaval, do samba, das ruas, dos shows e das boates gays (RIECHE; GASPARINI, 2010, p. 22-23).
\end{abstract}

Devido, em parte, ao preconceito com que passou a ser visto pelas elites letradas e, em parte, à dificuldade em concorrer com as novas formas de entretenimento que ganhavam cada vez mais espaço, sobretudo a televisão, uma novidade que atraía cada vez mais aficionados, o Teatro Musical perdeu o status que o consagrara como uma das expressões artísticas mais significativas da cultura brasileira entre o final do século XIX e grande parte do século seguinte (PRADO, 1999). Nesse mesmo diapasão, Rieche e Gasparini (2010) ressaltam o processo de guetificação do Teatro Musical ao afirmarem:

Portanto, após um longo reinado na cena, de 1884 a 1961, senhor do gosto do público, expondo-se em diferentes modalidades ou subgêneros, o teatro musical foi pulverizado, praticamente desapareceu dos palcos, deixou de ter continuidade de manifestação. As apresentações musicais se tornaram formas específicas de arte, não exatamente teatrais; foi a época de aparecimento e expansão dos programas de rádio e logo da televisão, dos shows, dos desfiles de escola de samba. Poucos foram os espetáculos, fora destes limites, que aconteceram como empreendimentos de teatro musical e atraíram a atenção do público. Por um longo período de tempo, dos anos 1950 aos anos 1980, as décadas que poderiam ser chamadas de obscuras, as manifestações teatrais do gênero aconteceram como intervenções eventuais, descontínuas. (RIECHE; GASPARINI, 2010, p. 23).

Por volta de 1961, o Teatro Musical foi pulverizado e praticamente desapareceu dos palcos. Foi exatamente na época do surgimento dos programas de rádio e televisão e desfiles de escolas de samba e shows de música. Foram muito poucos os espetáculos que aconteceram como empreendimento de Teatro Musical. As manifestações teatrais do gênero aconteciam como intervenções eventuais e descontinuas (SILVA, 2010). 


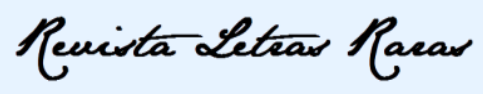

ISSN: 2317-2347 - v. 7, n. 1 (2018)

Entretanto, existia, ainda, um impulso que seria essencial reconhecer: o amor brasileiro pela música e pelos musicais, que, por fim, fez renascer o gênero musical de teatro.

\subsection{O renascimento}

O sucesso musical dos palcos foi contemporâneo à consolidação da música como prática de mercado e produto de consumo e logo o palco começou a buscar uma reaproximação com sua velha companheira de tablado - a música. Mas desta vez, ao invés da contemplação da cena europeia, o Teatro Musical brasileiro voltou seus olhos para o centro da cultura ocidental, Nova Iorque. A influência norte-americana gerou uma linha de trabalho e de sintonia teatral crescente e contínua entre os palcos brasileiros e a Broadway no teatro convencional, conforme apontam Rieche e Gasparini (2010, p. 24):

[...] o eclipse do musical nos palcos foi contemporâneo à consolidação da música como prática de mercado e realidade de consumo e logo o palco buscou se reaproximar da música, velha companheira de tablado. Já o segundo impulso trará um colorido diferente para a cena - assim como o teatro brasileiro do século XIX manteve um gesto permanente de contemplação da cena europeia, o do século XX registrou a mudança do centro da cultura ocidental, do velho continente para Nova Iorque.

Portanto, além da ascensão da música, um segundo fator de grande impacto no ressurgimento do Teatro Musical foi a influência dos Estados Unidos como novo centro cultural. Essa aproximação gerou dois eventos de grande repercussão. Tratava-se de duas produções isoladas que contribuíram para a aclamação de uma das grandes atrizes brasileiras do século XX, Bibi Ferreira. A primeira foi a montagem de My Fair Lady, de 1962, importada da Broadway pelos produtores Oscar Ornstein e Victor Berbara. Foi uma montagem rigorosamente fiel a original. Os protagonistas da trama eram Bibi Ferreira e Paulo Autran. Também compunham o elenco os atores Jaime Costa (barítono de projeção das antigas operetas), Suzana Negri, Estelita Bell, Elza Gomes, Sérgio Viotti e uma jovem, ainda anônima no coro, Marília Pera. O espetáculo alcançou um enorme sucesso, aclamação do público e reconhecimento da crítica, assim como a 


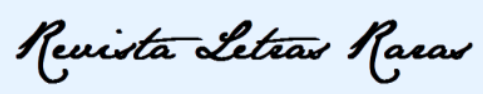

ISSN: $2317-2347$ - v. 7, n. 1 (2018)

montagem do musical Alô, Dolly! de 1966, produzida por Victor Berbara e protagonizada por Bibi Ferreira e Paulo Fortes (RIECHE; GASPARINI, 2010).

De fato, o talento de Bibi Ferreira foi relevante não apenas para essas produções como também para o próprio processo de reestruturação do Teatro Musical no país, uma vez que essa reestruturação foi complexa e difícil, conforme atestam Rieche e Gasparini:

\begin{abstract}
Apesar da aclamação do público e do reconhecimento da crítica, os dois feitos não foram suficientes para gerar uma linha de produção neste momento. $\mathrm{O}$ mais interessante é que esta seria a vertente de trabalho ideal para o talento de Bibi Ferreira, que alcançara imenso sucesso com os espetáculos Escândalos 1950 e Escândalos 1951 e que, de 1957 a 1960, foi uma estrela fulgurante de teatro de revista em Portugal. De toda a forma, o nome da atriz foi importante para a projeção de alguns musicais que chegaram ao palco neste período em que o gênero entrou em recesso e conheceu escassas montagens. Foram produções de grande porte ou de dimensões no mínimo razoáveis; elas reuniam nas fichas técnicas personalidades fortes da cena teatral brasileira ou mesmo da vida intelectual da sociedade e a listagem revela muito do perfil do período (RIECHE; GASPARINI, 2010, p. 26).
\end{abstract}

Os musicais que chegavam aos palcos neste período eram produções de grande porte e reuniam nas fichas técnicas personalidades já consagradas na cena musical brasileira, ou mesmo da vida intelectual. Em 1972, o musical O Homem da La Mancha, de Dela Wassermann, traduzido por Paulo Pontes e Flávio Rangel, ganhou destaque. As canções eram assinadas por Chico Buarque de Holanda e Ruy Guerra e a direção ficou a cargo de Flávio Rangel. No elenco, os três principais nomes eram Bibi Ferreira, Paulo Autran e Grande Otelo. A montagem inaugurou o Teatro Adolpho Bloch e seguiu para diversos teatros, tendo uma carreira de casa cheia (RIECHE; GASPARINI, 2010).

De acordo com Prado (1999), além da aproximação e do reconhecimento das qualidades dos palcos americanos houve também uma série de espetáculos que procuravam unir a música popular brasileira a uma nova forma de teatro. Foi a série Arena conta..., de Augusto Boal: Arena conta Zumbi e Arena canta Bahia, ambas de 1965; Arena conta Tiradentes, de 1967; e Arena conta Bolívar, de 1970. Ainda segundo o historiador do teatro brasileiro, as peças dedicadas a Zumbi e a Tiradentes tiveram como coautor Gianfrancesco Guarnieri, revelando a condição híbrida do musical deste 


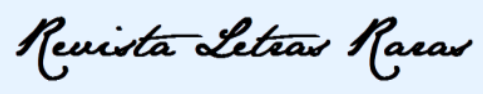

ISSN: 2317-2347 - v. 7, n. 1 (2018)

momento, já que um dos autores transitava pelo teatro de texto e o outro pelo Teatro Musical (CAMPOS, 1988).

Vale a pena mencionar que no período do regime militar, o gênero mencionado marca presença na resistência política, com espetáculos como Roda Viva, 1968, Calabar (censurada, dias antes de estrear), 1975, e Ópera do Malandro, 1978, todos de Chico Buarque. Outro espetáculo de Augusto Boal repercutiu muita discussão foi O Corsário do Rei, de 1985 (MALUF; AQUINO, 2006). Conforme Guinsburg, Faria e Lima (2006), também se destacou a montagem de Gota d'Água, de 1975, também escrita por Chico Buarque e Paulo Pontes. Era uma característica dos espetáculos desta época serem considerados um tipo de Teatro Musical político ou engajado. A peça Gota d'Água transpunha para a atualidade do milagre econômico brasileiro (sob os governos militares), o mito de Medeia, que foi representada com grande impacto por Bibi Ferreira e com a direção de Gianni Ratto.

Outra montagem que foi importante para esse segmento de teatro político musicado foi Vargas, de 1983, de Dias Gomes e Ferreira Gullar, com a direção de Flávio Rangel, cenografia de Gianni Ratto e as músicas ficaram sob a responsabilidade de Chico Buarque e de Edu Lobo. O elenco era composto de notáveis intérpretes como Paulo Gracindo no papel principal, Grande Otelo, Isabel Ribeiro e Oswaldo Loureiro, encarregado de materializar a personagem de Lacerda/Tucão (MALUF; AQUINO, 2006).

Nesse mesmo ano, a atriz Bibi Ferreira foi responsável por um outro momento de grande impacto teatral, ao interpretar a famosa cantora francesa Édith Piaf. O espetáculo com texto de Pam Gems tinha como título o nome da cantora Piaf e direção assinada por Flávio Rangel. A atuação de Bibi fez com que o espetáculo conseguisse um extremo sucesso, sendo apresentado em diferentes formatos e recitais (com mais dramatização, ou numa versão menos extensa), mas sempre com a principal função de materializar o ato de cantar os grandes sucessos da homenageada. Piaf foi uma contribuição bastante favorável para fortalecer a linha dos musicais biográficos e de exposição de acervos artísticos de grandes intérpretes (MALUF; AQUINO, 2006).

Já em meados dos anos 1980, o panorama artístico brasileiro voltou a se tornar favorável ao Teatro Musical, propiciando a instauração de um novo ciclo para essa expressão artística. De fato, a instituição do regime democrático e, portanto, a queda da 


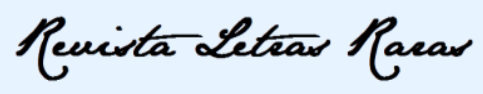

ISSN: $2317-2347$ - v. 7, n. 1 (2018)

censura que tolhia a potencialidade criativa dos artistas, favoreceu a criação de espetáculos com temáticas mais variadas, ampliando o repertório e as possibilidades de encenação. Acrescente-se a isso o saudosismo dos produtores e artistas em relação ao êxito logrado pelo Teatro Musical no país quando do apogeu desse gênero. O desejo de alçar o gênero ao status obtido no passado favoreceu a produção de trabalhos de qualidade, resultantes do esforço coletivo em prol da arte (MEDAGLIA, 2008).

Um exemplo desse novo fôlego foi o aparecimento do grupo Dzi Croquetes. Os integrantes do grupo diziam que eram feitos de carne, assim como croquetes. Foi a partir dessa conclusão que, sentados numa mesa de bar, alguns artistas decidiram nomear o seu recém-criado grupo:

A repetição da letra 't' e o 'Dzi' (um aportuguesamento espirituoso do artigo da língua inglesa 'the') foram inspirados no conjunto norteamericano The Coquettes. E assim, com humor e criatividade, uma das maiores manifestações de contracultura da História do Brasil ganhou forma. Em julho deste ano, depois de ter rodado o mundo em festivais de cinema, um filme sobre essas figuras tão controversas entrou em cartaz em diversas cidades do país (MOREIRA, 2010, s.p.).

Realmente, o grupo marcou época e conseguiu, inclusive, conquistar projeção no exterior. Os sapatos eram de salto alto e as roupas femininas, propositalmente exibiam as pernas cabeludas e a barba cultivada pelos homens do grupo, usavam cílios postiços, purpurina, plumas. Assim, treze jovens entravam em cena, escandalizando o público e, é claro, os censores. A irreverência, a iconoclastia do grupo foi um acontecimento no Brasil. Trouxeram para a cena um espírito libertário e invenção artística, mudando o conceito de espetáculo daquela época: os Dzi, como eram chamados, não foram apenas atores ou dançarinos (BUDAZS, 2008). O caráter transgressivo do grupo é reiterado pela historiadora Julia Moreira (2010), que elenca as influências que tiveram papel decisivo na formação dessa companhia:

Os Dzi Croquettes eram uma mistura entre espírito libertário e invenção artística. Eles foram influenciados por diferentes manifestações culturais, como o teatro de vanguarda, o jazz, a bossanova e o movimento gay. Com o passar do tempo, se tornaram influência para outros artistas, inclusive para o teatro de humor que ficou conhecido como besteirol, e se consagrou com programas de televisão como Armação Ilimitada e TV Pirata. Além disso, eles foram a semente para a criação do grupo musical "As Frenéticas" (MOREIRA, 2010, s.p). 


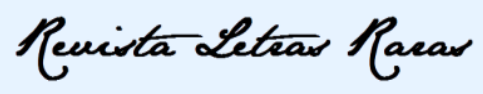

ISSN: $2317-2347$ - v. 7, n. 1 (2018)

Outro fato relevante no decênio de 1980 foi a montagem-xerox de A Chorus Line, em 1984. Escrita por James Kirkwood e Nicholas Dante, sob direção musical de Murilo Alvarenga, o espetáculo se notabilizou por ser uma arrojada adaptação de um grande sucesso da Broadway (MALUF; AQUINO, 2006). A visão esquemática do período impõe, ainda, a localização de alguns outros episódios, como as encenações de Theatro Musical Brazileiro - Parte II (1914/1945), roteiro de Luiz Antônio Martinez Correa e Marshall Notherland, direção de Luiz Antônio Martinez Correa; As Noviças rebeldes, de Dan Goggin (tradução de Flávio marinho), com a direção de Wolf Maia; e A Estrela Dalva, de Renato Borghi e João Eliseu, protagonizado por Marília Pêra. Essas foram montagens que marcaram o ano de 1987. Nesse momento, três vertentes claras de criação apareceram definidas na cena de ressurgimento do musical carioca: a pesquisa e os estudos históricos, a temperatura do mercado internacional e a busca dos mitos da MPB (GUINSBURG; FARIA; LIMA, 2006). Destacam-se também outras produções que, reunidas, produzem um caldo cultural efervescente ao final do século XX:

No final dessa década, Antonio De Bonis inaugura o gênero biográfico com Lamartine para Inglês Ver, 1989, que tem direção musical de Jacques Morelenbaum. Retoma o tema em Lamartine II - o Resgate, 1993, e, dois anos depois, escreve e dirige Éno Toco da Goiaba. O gênero começa a ser explorado, com os espetáculos de Pixinguinha, de Fátima Valença, e O Samba Valente de Assis, de Zé Trindade Neto, ambos em 1995. No ano seguinte, estréia Metralha, texto e direção de Stella Miranda, sobre a vida de Nelson Gonçalves (ITAÚ CULTURAL, 2013, s. p).

O êxito desse Teatro Musical revigorado, longe de se restringir ao final do século XX, avança também rumo ao novo século e milênio, mostrando-se capaz de se reinventar para se reerguer do ostracismo em que esteve imerso. Alguns espetáculos provenientes da Broadway, como Les Misérables, Chicago e O Fantasma da Ópera, não só conseguem grande êxito de público como também recebem adaptações brasileiras, haja vista o trabalho desenvolvido por Cláudio Botelho, que, juntamente com Charles Moeller, produz espetáculos como Company (2001), e Lado a Lado com Sondheim (2005), com atores que apresentam a desenvoltura técnica do modelo da Broadway. Nessa mesma perspectiva, o diretor Wolf Maya dirige uma série de musicais que também assumem um estilo americanizado, pautado em uma trama simples que funciona como subterfúgio para a criação de números (ITAÚ CULTURAL, 2013). 


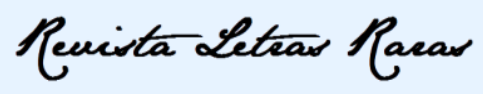

ISSN: 2317-2347 - v. 7, n. 1 (2018)

A aproximação entre dois universos bastante opostos tem um contorno especial, pois trabalha com um campo cultural de extrema riqueza para a formulação de um Teatro Musical impactante. O desenho da linha dramatúrgica aponta uma identidade curiosa entre dois mundos poéticos distantes, pois se trata do reconhecimento da elevação e da altivez que definem os princípios do samba brasileiro.

\section{Exemplo de adaptação do estilo Broadway no Brasil}

Esta seção traz um exemplo de adaptação de musical estrangeira em terras tupiniquins. O musical intitulado Priscilla, rainha do deserto estreou no Brasil em 16 de março de 2012, no Teatro Bradesco, do Bourbon Shopping, em São Paulo, um ano após a estréia na Broadway. Para entender a força da recepção dessa obra, é preciso acentuar que ela percorreu diversos países mundo afora conquistando milhões de espectadores. Para que se possa perceber a atualidade e a especificidade da consolidação do gênero no Brasil torna-se necessário apresentar as diferenças e semelhanças de tal gênero em relação ao que o inspirou.

Vale destacar que na Austrália o espetáculo havia sido apresentado em 2006, no Lyric Theather, de Sydney, o que não é de se espantar visto que a peça é baseada em um filme que foi dirigido pelo australiano Stephan Elliott (1994) que em 1995 venceu o Oscar de melhor figurino. Na obra cinematográfica, Priscilla é o nome do veículo que duas drag queens (Anthony/Mitzi e Adam/Felícia) e uma transexual (Bernadette/Ralph) utilizam - um ônibus cor-de-rosa - ao cruzar a Austrália. No filme, elas cruzam o estado porque foram contratadas para fazer um show de Drag Queen em um resort em Alice Springs, uma cidade turística do deserto australiano, situada no norte do estado. Tendo sido filmado e dirigido na Austrália, o filme apresenta peculiaridades ligadas a contextos australianos o que, por si só, já dificultaria a adaptação.

$\mathrm{Na}$ adaptação brasileira, alguns números musicais remetem ao filme de 1994, como Shake Your Groove Thing; Go West; I Love The Night Life; I Will Survive. Já outras músicas que passaram a fazer parte apenas nos espetáculos teatrais foram It's Raining Men; Say a Little Prayer; Hot Stuff e True Colors. Um fato imprescindível a ser mencionado é que as músicas, para a adaptação brasileira do musical, não foram 


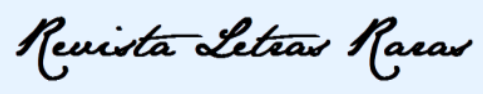

ISSN: 2317-2347 - v. 7, n. 1 (2018)

traduzidas, seguindo-se, portanto, a utilização das originais e o elenco foi composto apenas de atores brasileiros, somando 27 ao todo.

Não se pode deixar de mencionar alguns elementos relacionados à adaptação: primeiro houve o filme produzido na Austrália (1994), depois a adaptação para palcos australianos (2006). Então, foi adaptado para países de língua inglesa, entre eles os EUA. Finalmente, foi adaptado para os palcos brasileiros, país de idioma oficial completamente diferente dos demais. Daí a decisão de a peça no Brasil ter atores nacionais não ter sido mera coincidência. Vale mencionar que a adaptação brasileira do texto foi realizada por Flávio Marinho. A suntuosidade da peça pode ser exemplificada não somente pelos figurinos detalhados, mas também pelo veículo rosa que é utilizado: o ônibus foi importado de Londres e nunca sai de cena porque pesa oito toneladas (quase o peso de um elefante adulto), conta com 30 mil pontos de LED e chegou no Brasil através de um navio. Trata-se do mesmo veículo que foi utilizado na adaptação londrina. O figurino foi de Tim Chappel, premiado no Oscar de 1994 pelas roupas criadas para o filme. As audições para a peça iniciaram em abril e foram até agosto de 2011 para elencar artistas não conhecidos no ramo televisivo. As músicas não foram traduzidas.

Nas apresentações musicais de Sydney e de Londres, Adam alimenta o sonho de atravessar uma montanha cantando singles da cantora australiana Kylie Minogue. Nas adaptações da Broadway e do Brasil, a referência à cantora australiana foi substituída pelo nome da cantora Madona, que é mais conhecida nos EUA e em solo brasileiro que a cantora australiana mencionada. Tal característica de adaptação mostra a interlocução e a influência cultural dos Estados Unidos no Brasil. Tanto que, ao realizar o sonho, na peça australiana é uma música da cantora australiana que o personagem canta, intitulada Confide in Me e, nas adaptações estadunidense e brasileira, é a música Like a Prayer, de Madona, que tem aparição.

Como algumas cenas exigem capacidade vocal mais expressiva, optou-se pela dublagem de hits como Go West, do Village People e I Say A Little Prayer For You, de Dionne Warwick, que são apresentadas por profissionais - as chamadas Divas - com quem os atores dividem o palco no Brasil durante a apresentação das músicas mencionadas. No espetáculo brasileiro três atrizes cantam ao vivo enquanto as drags 


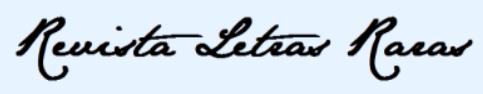

ISSN: 2317-2347 - v. 7, n. 1 (2018)

dublam, para evitar que o público ouça versões gravadas das músicas que aparecem na trama.

No musical brasileiro alguns nomes foram preservados no idioma inglês, noutros foram substituídos por cenários reconhecíveis pelo público brasileiro. Quando, num dos diálogos do musical da Broadway, o monte Ruschmore é mencionado, aquele no qual estão esculpidos rostos de ex-presidentes estadunidenses, no musical brasileiro tal referência é substituída pelo Cristo Redentor, um monumento carioca familiar aos brasileiros. Por outro lado, séries mencionadas no filme australiano não poderiam ser preservadas sob pena de não serem reconhecidas pelo público. Um fato curioso, também relacionado ao Rio de Janeiro, é que Stephen Elliot afirmou, em entrevista veiculada para a imprensa brasileira, que teve a ideia para o filme em 1989 quando estava visitando o Rio de Janeiro durante o carnaval. No meio da multidão ele avistou uma drag e pensou "Tenho que levar uma drag para o deserto da Austrália" (apud MEDEIROS, 2012, s. p.).

Para citar um exemplo em que houve autorização do diretor australiano para adaptações na língua portuguesa pode ser mencionado o nome da boate que aparece na cena de abertura do musical. Em inglês, a boate se chama Cockatoo Club e, em português passou a se chamar Peru-Ação. A apresentadora do lugar em inglês se chamava Miss Understanding e, em português, foi traduzida para Miss segura (que produz o efeito de humor "mi segura"). Noutros casos, as versões estadunidenses prevaleceram: as séries australianas Baywatch (1989-1999) e Crime Watch (1984-2012) foram substituídas pelos filmes Pretty Woman (1990) e Pulp Fiction (1994), respectivamente, que se referem a filmes mais populares, preservando, no entanto, nomes em inglês e não os nomes traduzidos para o português.

Uma produção milionária como esta não serve apenas para fazer rir. Ela traz consigo leituras da sociedade moralista na qual nos situamos. Não é a toa que o filme e as adaptações seguem sendo atuais porque a temática está relacionada ao preconceito, à vergonha, aos rótulos e, assim, a cada um dos que constituem o público que a assiste. Mais do que falar de adaptações nacionais de peças estrangeiras o que se propõe aqui é exemplificar que a Broadway e outras produções podem ganhar contornos tupiniquins para se fazer presente em cenários nacionais cada vez mais abrangentes. Se no filme e nas peças as personagens fazem rir elas também tem potencial para comover visto que 


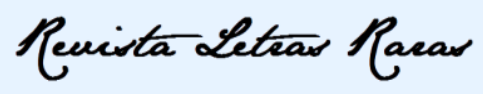

ISSN: $2317-2347$ - v. 7, n. 1 (2018)

sofrem homofobia durante o enredo. O absurdo não é o que está sendo retratado, é que ele não é apenas matéria de ficção, pois continua sendo sentido na pele por diversos homossexuais fora das telas, cotidianamente. É aí que a arte manda recado e deixa sua marca, mesmo depois de duas décadas de lançamento do filme que inspirou os musicais.

\section{Considerações finais}

Este trabalho buscou contribuir para a historiografia do Teatro Musical no Brasil ao proceder a uma pesquisa fundamentada no levantamento de obras de referência, resultando em contribuições relacionadas a uma apresentação do estado da arte acerca da evolução histórica e estética de tal gênero artístico em âmbito nacional. A primeira seção apresentou a introdução temática do artigo. Na segunda seção foram apresentadas as três fases da recepção na história do Teatro de Revista no Brasil: a primeira fase, mais centrada no enredo coeso do que na articulação corporal e o empreendimento de críticas ao modo de vida social; a segunda na qual prevaleceu o impacto da cultura estadunidense e a ênfase na nudez feminina; a terceira que se destacou pelos fartos investimentos em megaproduções.

Na terceira seção o Teatro Musical brasileiro aparece como uma prática que existe desde meados do século XIX sob influência da França e de Portugal e foi ganhando terreno apesar das críticas da elite, de intelectuais e de escritores que o combateram devido ao fato de considerarem-no indecoroso e alheio a tradições culturais nacionais sob a mira frequente, tanto na Europa quanto no Brasil, da vigilância moralista e repressora da época. Para se ter uma ideia da interlocução cultural entre Brasil e o continente europeu podemos citar Orpheu no inferno, uma opereta importada, por exemplo, foi apresentada em Paris em 1850 e no Brasil em 1865.

Cabe acentuar que o público em geral apresentava dificuldade de reconhecer o teor satírico e intertextual com formas de arte estrangeiras o que fez com que Orfeu na Roça fosse apresentada em 1868, a partir de uma releitura de Orfeu e Eurídice. Era uma paródia brasileira sendo apresentada como releitura de uma paródia francesa. Mérito do artista Francisco Vasques que operou modificações considerando a realidade brasileira, o que fez com que tal ação resultasse em mais de uma centena de apresentações. 


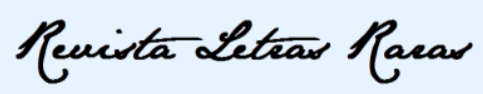

ISSN: 2317-2347 - v. 7, n. 1 (2018)

Vale destacar, com Prado (1999), que o Teatro Musical no Brasil absorve um vasto leque de manifestações, o que dificulta sua caracterização. No caso brasileiro, o musical tomou forma mais nítida no início do século XIX, mas começou a se impor como acontecimento social e cultural no século $\mathrm{XX}$ tendo sido palco para diversos compositores nacionais (como Chiquinha Gonzaga, Tom Jobim, Ary Barroso e Carlos Gomes) que viram na música uma forma de aproximação com o público. Não se pode deixar de mencionar que também nas primeiras décadas do século XX o Teatro Musical era visto como forma de arte inferior ao Teatro convencional o que resultou, gradualmente, na sua marginalização. Entre o final do século XIX e parte do século seguinte, o Teatro Musical foi perdendo terreno devido à dificuldade em concorrer com as novas formas de entretenimento que ganhavam cada vez mais espaço, sobretudo a televisão. Por volta de 1961 ele praticamente desapareceu devido ao surgimento dos programas de rádio e televisão e desfiles de escolas de samba e shows de música.

Então, a segunda subseção da seção 3 traz informações acerca de seu ressurgimento que, dessa vez, ao invés de se voltar para a cultura europeia, voltou-se para a cultura estadunidense, mais especificamente, a cultura nova-iorquina o que possibilitou articulações entre o palco brasileiro e a influência das apresentações da Broadway. A ascensão dos EUA como novo centro cultural repercutiu na apresentação de uma das mais conhecidas artistas da cena teatral brasileira do século XX que atuou em peças importadas da Broadway aqui no Brasil: Bibi Ferreira. Dessa forma, a restruturação do Teatro Musical em terras tupiniquins foi complexa considerando que além da aproximação e do reconhecimento das qualidades dos palcos americanos, houve também, uma série de espetáculos que procuravam unir a música popular brasileira a uma nova forma de teatro. Tal cenário possibilitou peças com teor de resistência no período da ditadura militar brasileira ${ }^{3}$ e também peças dedicadas a Zumbi dos Palmares e Tiradentes, o que já apontava para um espectro teatral que aos poucos foi extrapolando a apropriação exterior artística em solo nacional. Finalmente, a última seção trouxe um exemplo de adaptação de uma apresentação estrangeira em solo brasileiro.

\footnotetext{
${ }^{3}$ Para aprofundamento, vale mencionar que José Fernando Marques de Freitas elaborou sua Tese de Doutoramento defendida em 2006 na Universidade de Brasília a partir do tema.
} 


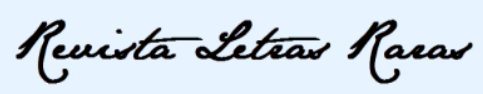

ISSN: 2317-2347 - v. 7, n. 1 (2018)

Dessa forma, o trabalho buscou demonstrar que o Teatro Musical, o Teatro de Revista, a Ópera, a Opereta e outros gêneros foram mais do que manifestações culturais importadas da Europa ou dos Estados Unidos. De fato, essas expressões artísticas são exemplos de como, por meio de um trabalho de tradução cultural, padrões estéticos advindos de outros países são acomodados à cultura brasileira e assumem uma configuração específica, deixando de ser meras cópias ou importações. Não se pode deixar de lado o alto custo dos ingressos, a inacessibilidade do teatro musical à maioria da população e a falta de incentivo para que ações públicas se concretizem visando o encontro com mais espaços em que esta cultura esteja presente. Mais do que incentivo financeiro, o que o teatro musical precisa é buscar meios de inserir-se na cultura brasileira. Mas isso, como bem sabemos, não se faz do dia pra noite...

\section{REFERÊNCIAS}

BUDAZS, R. Teatro e Música na América Portuguesa. Curitiba: UFPR, 2008.

CABRAL, S. No tempo de Ari Barroso. Rio de Janeiro: Lumiar, 1993.

CAMPOS, C. de A. Zumbi, Tiradentes E Outras Histórias Contadas pelo Teatro de Arena de São Paulo. São Paulo: Perspectiva, 1988.

FENERICK, J. A. Nem no morro nem na cidade: as transformações do samba e a indústria cultural (1920-1945). São Paulo: Annablume, 2005.

FREITAS, J. F. M. de. Com os séculos nos olhos: teatro e expressão política no Brasil, 1964-179. 2006. 386 f. Tese (Doutoramento em Literatura Brasileira). Universidade de Brasília, Brasília.

GUINSBURG, J.; FARIA, J. R.; LIMA, M. A. de. Dicionário do teatro brasileiro. São Paulo: Perspectiva, 2006.

ITAÚCULTURAL. Teatro Musical. Disponível em: [http://www.itaucultural.org.br/aplicexternas/enciclopedia_teatro/index.cfm?fuseaction =conceitos_biografia\&cd_verbete=5891]. Acesso em: 22 de nov. de 2014 .

MACAU, C. Ao estilo Broadway. 1 de julho de 2016. Disponível em: [https://www.revistacontinente.com.br/edicoes/187/ao-estilo-broadway]. Acesso em: 27 de abril de 2018.

MAGALDI, S.; VARGAS, M. T. Cem Anos de Teatro em São Paulo: (1875-1974). São Paulo: Senac, 2000.

MALUF, S.; AQUINO, R. (Orgs.). Dramaturgia em Cena. Maceió; Salvador: EdUFAL/EDUFBA, 2006.

MEDAGLIA, J. Música, maestro! Do canto gregoriano ao sintetizador. São Paulo: Globo, 2008. 


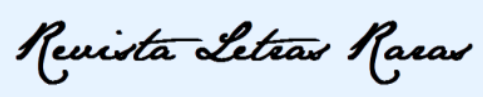

ISSN: 2317-2347 - v. 7, n. 1 (2018)

MEDEIROS, E. Adaptação musical de 'Priscila, rainha do deserto' estreia nesse sábado São Paulo. Disponível em: [https://entretenimento.uol.com.br/noticias/redacao/2012/03/17/adaptacao-musical-depriscila-rainha-do-deserto-estreia-neste-sabado-em-sao-paulo.htm]. Acesso em: 27 de abril de 2018.

MENCARELLI, F. A Cena Aberta: A absolvição de um Bilontra e o teatro de revista de Arthur Azevedo. Campinas: Ed. da Unicamp, 1999.

MENSCH CULTURA. Cultura: Teatro Musical made in Brasil. 27 de fevereiro de 2014, s. p. Disponível em: [http://revistamensch.com.br/cultura-teatro-musical-made-inbrasi/]. Acesso em: 27 de abril de 2018.

MOREIRA, J. Dzi Croquettes. Revista de História, agosto de 2010. Disponível em: [http://revistadehistoria.com.br/secao/reportagem/dzi-croquettes]. Acesso em: 29 de nov. de 2014.

PRADO, D. de A. História concisa do teatro brasileiro: 1570-1908. São Paulo: Edusc, 1999.

PRISCILLA, A RAINHA DO DESERTO (filme). Direção de Stephan Elliott. PolyGram Filmed Entertainment, 1994. 1 DVD (103 minutos). Título original: The adventures of Priscilla, Queen of the Desert.

PRISCILLA, QUEEN OF THE DESERT (musical da Broadway). Roteiro de Stephan Elliott e Allan Scott. Sydney (Austrália), 2006, Londres, 2009, Broadway, Nova Iorque (E.U.A.), 2011. Disponível em: [http://www.priscillathemusical.com]. Acesso em: 26 ago. 2013.

PRISCILLA, RAINHA DO DESERTO (musical adaptado no Brasil). Direção de Simon Philips. Roteiro, letras e canções: Flávio Marinho. Teatro Bradesco, São Paulo (SP), 2012. (150 min.).

RIECHE, E.; GASPARINI, G. Em busca de um teatro musical carioca. São Paulo: Imprensa Oficial do Estado de São Paulo, 2010.

SEVERINO, T. S. O gênero discursivo Musical: um caminho para o Letramento. Maringá, PR: Universidade Estadual de Maringá, 2007.

SILVA, T. B. Passos, letras, notas e interdições - pequeno estudo do teatro musical carioca. In.: Anais do VI Congresso de Pesquisa e Pós-Graduação em Artes Cênicas, p. $1-5,2010$.

VENEZIANO, N. Não adianta chorar: Teatro de revista brasileiro...oba! Campinas: Editora da UNICAMP, 1996.

VENEZIANO, N. O Teatro de revista no Brasil: Dramaturgia e convenções. Campinas: Editora da UNICAMP/Pontes, 1991. 